\title{
Algumas questóes antropológicas a partir do programa de inclusão racial da Universidade Federal do Paraná
}

\author{
MARCOS SILVA DA SILVEIRA
}

Inicialmente, este artigo deveria ter um caráter introdutório, apresentando meus primeiros questionamentos sobre os anos que passei à frente do NAPA e do NEAB na UFPR. ${ }^{1}$ Nestes termos, seria basicamente uma versão resumida do projeto que apresentei ao pós-doutoramento no PPGAS do Museu Nacional, no ano de 2014, sob a orientação de Antonio Carlos de Souza Lima, no LACED². O projeto estava voltado para a análise das políticas de inclusão racial enquanto políticas públicas que mereciam um olhar antropológico tanto pelo tema - a inclusão de negros e índios no ensino superior - quanto pelo debate que suscitaram no meio antropológico desde o início da sua implementação, há mais de dez anos.

No pós-doutorado, acabei optando por trabalhar com o tema das bancas de verificação da autodeclaração étnico-racial, que foram alvo de muita polêmica nos meios acadêmicos, nas mídias e no debate sobre políticas afirmativas como um todo. Etnografando a partir da minha participação nessas bancas entre os anos de 2009 e 2012 e o desenrolar das mesmas, eu discutia alguns pontos que vale a pena retomar nesta introdução.

Apesar de todas as polêmicas em torno delas, as bancas ocorriam com relativa tranquilidade. Eram muito mais desgastantes para quem participava delas do que qualquer outra coisa. A maior parte dos candidatos tinha sua autodeclaração conferida sem maiores problemas. Cerca de dez por cento dos candidatos tinham sua autodeclaração questionada, dos quais metade terminava passando pela avaliação e a outra metade não. Neste processo de questionamento muito do que se discutia em torno destas

1 NAPA: Núcleo de Acompanhamento das Políticas Afirmativas, criado pelo reitor Zaki Akel em 2009 para centralizar as políticas inclusivas para indígenas, deficientes e negros. NEAB: Núcleo de Estudos Afro-brasileros. O NEAB da UFPR faz parte de uma rede de NEABs existentes em diversas instituições de ensino superior no País.

2 LACED - Laboratório de Pesquisas em Etnicidade, Cultura e Desenvolvimento. 
políticas vinha à tona, o que fazia destes questionamentos um objeto privilegiado para uma análise antropológica em torno do(s) sistema(s) de classificação de referência. Basicamente, havia e ainda há uma dificuldade não em definir quem é Negro em relação a quem é Branco, ou vice-versa, mas quem é Pardo em relação a quem é Preto e em relação a quem é Branco, indígena, oriental etc.. Era preciso distinguir os Pardos Negros, aptos para a cota racial, de outros conjuntos de pardos, fossem pardos morenos ou aqueles que poderiam ser descrito como "inclassificáveis". Pardos morenos, geralmente de origem latina, eram facilmente descartados. $\mathrm{O}$ objetivo primeiro dessas bancas era impedir o acesso destas pessoas e isso não causava problema algum. Tais pessoas nunca recorriam da decisão das bancas; os processos judiciais pedindo revisão vinham dos pardos inclassificáveis, quando sua autodeclaração não era deferida, principalmente em cursos de concorrência alta.

O fato de que a categoria Pardo, dentro de um quadro de classificações étnico-raciais, não permite uma classificação precisa vem sendo discutido nas ciências sociais brasileiras há certo tempo, e precisa ser mais bem compreendido, a partir desta experiência, pois tem implicações numa política pública voltada para Pretos e Pardos.

No pós-doutoramento, eu argumentava que os problemas da classificação "étnico-racial" enfrentados pela banca da UFPR tinham origem num problema maior da sociedade brasileira, que não tem critérios classificatórios necessários a este esforço. O que existe, como pesquisadores que discutiram bem o tema, Lilia Schwartz e João Pacheco de Oliveira, afirmam, é uma categoria que nada define Pardo - mas que é fundamental, não para classificar cores e raças da população, mas para inviabilizar qualquer tentativa de classificação, em nome do princípio da mistura e da miscigenação que ela exprime e mede. Vale a pena, inclusive, pensar que desde seus primeiros usos em Censos, a categoria Pardo aponta para um país pensado em termos de Brancos e Mestiços, e que mantê-la em políticas que pensam Negros em oposição a Brancos é problemático. A categoria Negro pode acabar vindo a substituir essa antiga noção de Pardo, aquele que é um "não branco", perdendo a sua força política neste processo.

Como esta categoria não define o pertencimento a um grupo social específico, seja racial, étnico, religioso ou regional, como lidar com ela quando se precisa definir se um cidadão faz jus a uma política pública inclusiva voltada para um determinado público-alvo, que precisa ser validada de alguma forma, tomando-a como referência? A República brasileira trabalha com um sistema de identificação de cidadãos que é totalmente individualista e não reconhece identidades coletivas, sejam étnicas, regionais ou religiosas, exceto no plano da cultura. No plano dos direitos civis e da organização social, ao contrário, qualquer tentativa de reivindicar uma identidade coletiva sempre é vista como uma ameaça à unidade nacional, de uma nação sincrética e mestiça. Muito do incômodo e das críticas que as políticas de inclusão racial no ensino superior sofrem deriva desta característica de nossa sociedade atual.

Na prática, e isso também sempre foi alvo de algum questionamento, as bancas trabalhavam com critérios presumidos oriundos do senso comum da cultura brasileira sobre Cor e Raça para avaliar o fenótipo dos candidatos e, por isso mesmo, esbarravam em tipos mestiços impossíveis de serem classificados de outra forma.

Mesmo assim as bancas existiram e cumpriram o seu papel de evitar que pessoas de tipos "morenos" entrassem em cursos mais disputados, alegando serem "pardas". Permitiam que a Universidade 
tivesse um acompanhamento mínimo dos candidatos que estavam entrando pelas cotas raciais e era também um momento de encontro entre pesquisadores, militantes e estudantes negros e simpatizantes de suas causas, no qual os resultados desta política de inclusão racial podiam ser conferidos.

A partir de 2013, com a vigência da lei federal de cotas para o ensino superior (Lei 12.711/2012), essas bancas deixaram de existir, o que causou uma série de situações desestimulantes. A maioria dos participantes do processo das cotas raciais reclamou e pedia que as bancas fossem mantidas, até que os funcionários responsáveis pelo registro acadêmico começaram a se queixar de que não havia mais "candidatos pretos" entrando pelas cotas, e que havia pessoas brancas entrando pela cota racial, alegando ter algum tipo de ancestral negro. A insatisfação foi crescendo entre os anos de 2014 e 2015, até que a Procuradoria da Universidade considerou que as bancas poderiam voltar, sem ferir os termos da autoidentificação da lei federal. Algumas reuniões foram feitas para sistematizar essa nova banca, que deveria atender aos candidatos negros e aos candidatos indígenas, já que é necessário definir bem os termos de uma nova resolução, incorporando a experiência das bancas anteriores. Por isso mesmo, resolvi escrever um texto mais conclusivo, explorando algumas questóes importantes para esse novo momento e mantendo a inspiração inicial deste artigo, de apontar temas para a pesquisa antropológica em torno da inclusão racial nas universidades públicas.

\section{Negros ou pretos e pardos?}

No final de 2016, o NEAB - Núcleo de Estudos Afro-brasileiros da UFPR convocou uma reunião para a discussão da versão final de uma resolução que "estabelece procedimentos e critérios para validação de autodeclaração nos processos seletivos para ingresso nos cursos de graduação da UFPR e dá outras providências".

Foi uma reunião interessante, pude reencontrar os antigos companheiros do Movimento Negro curitibano que participavam das primeiras bancas. Foi um momento de reencontro, de relembrar as discussões do passado e de como elas nos preparam para este novo momento. Também havia pessoas mais novas, de novos coletivos negros, reproduzindo um velho problema destas reunióes do NEAB. Pessoas recolocando pautas já há muito discutidas ou trazendo questões que não estavam na pauta daquela reunião. Felizmente, os membros antigos do NEAB e do Movimento Negro também já haviam aprendido a lidar com essas tendências dispersivas.

O texto em questão era pequeno, de três páginas, com poucos pontos polêmicos. Eu apresentei, a partir das reflexões do meu pós-doutorado, se não seria melhor substituir a noção de "candidatos pretos e pardos” por candidatos negros, já que, em tese, as cotas são para negros, e a noção de que Negros são os "pretos e pardos" causa uma série de confusões. Basicamente, no tempo da primeira banca, definir se todos os pardos eram realmente negros sempre foi o maior problema. No esforço de entender as dificuldades da banca diante da verificação da autoidentificação dos pardos como negros eu retomara a questão de que pardo não é uma categoria nem étnica nem racial, algo complicado uma vez que a maioria dos candidatos negros fosse, de fato, autodeclarada parda. De que categoria social estávamos falando, afinal? 
Os membros antigos do movimento negro apoiaram esta ideia, que eu já tinha conversado com outros intelectuais em outros momentos, mas me surpreendeu que a atual coordenadora do NEAB discordasse mais ou menos nos seguintes termos: "Negro é uma categoria abrangente, pode ser muita coisa, muitas pessoas podem ser negras de diferentes maneiras. Preto epardo são as categorias do IBGE, que servem melhor aos termos das leis de cotas".

Este argumento acabou prevalecendo, de que o texto da resolução da UFPR deveria manter as categorias "legais" do Estado Brasileiro para pensar tal tipo de política, embora, na prática, dentro do NEAB a categoria fundamental seja Negro, termo utilizado realmente de maneira bastante abrangente com diversos sentidos.

Achei a colocação interessante, pois formulava uma distinção entre o ser Negro dos Movimentos Negros e o preto, pardo - e o indígena - do IBGE e das políticas públicas. Como situar esta diferenciação entre uma noção abrangente dos movimentos sociais e uma noção restritiva das políticas governamentais? Como elas se situam uma em relação à outra e o que podemos entender sobre essas relações possíveis?

O ponto em questão na nova resolução vem a ser, como antes, a definição do fenótipo do candidato como o único critério a ser verificado. Se ele ou ela se encaixa na sua autodefinição, o que nos coloca numa dimensão muito individualizada desta autodefinição, sem considerar família e contexto cultural. Novamente retorna a questão dos sujeitos coletivos. Que identidade coletiva se define apenas a partir de fenótipos individuais? Qual é o pertencimento em jogo? Quando aconteceu a nova banca no vestibular de 2017, as pessoas que participaram, mais uma vez, comentaram as dificuldades em se lidar com os pardos, em contraste com a facilidade em se lidar com os pretos, que, no final das contas, sempre foram os candidatos preferenciais para as cotas para negros.

A questão envolvendo a categoria Negro diante das noções de preto e pardo do IBGE, e os desacertos entre ambas, não é apenas um detalhe etnográfico surgido no NEAB da UFPR. Na verdade, tal questão nos remete ao início das discussões sobre estes programas, já foi discutida por outros pesquisadores, assim como o uso da categoria Negro, também já sugerido ao longo do debate da sua implementação, debate este que vale a pena recuperar.

José Jorge de Carvalho narra, com relação à UnB, que ele e Rita Segato haviam proposto, já em 2004, a existência de cotas para negros e não para pretos e pardos, uma vez que a categoria pardo é ambígua e permitiria que pessoas morenas, não discriminadas por serem negras, se beneficiassem do Programa. A autoidentificação enquanto negro, entendida como uma categoria política, seria suficiente para a inscrição do candidato. A comissão de implementação de cotas da UNB, por sua vez, optou pela identificação de pretos e pardos. Primeiro o candidato deveria se declarar preto ou pardo, para depois ser considerado Negro pela Universidade. Para evitar fraudes, os candidatos, como na UEMS, ${ }^{3}$ deveriam posar para uma foto, que seria avaliada por uma comissão. Em caso de recusa, o candidato poderia recorrer e seria ouvido pela comissão (Carvalho 2005:186).

3 Universidade Estadual do Mato grosso do Sul, que também instituiu cotas raciais e trabalhava com bancas de verificação, utilizando-se de fotos. 
A existência desta comissão na UnB causou uma enorme polêmica e acabou encobrindo uma dimensão mais importante da proposta de Carvalho e Segato para as cotas raciais na UnB, a criação de um sujeito coletivo negro. Na proposta inicial os candidatos negros aprovados fariam matrícula todos juntos, para formarem, já na entrada na Universidade, um conjunto de estudantes negros. A existência de uma pessoa não negra, numa situação destas, seria bastante vexatória. Para os autores da proposta, a necessidade de se verificar a autodeclaração despolitiza o programa de cotas, uma vez que a opção por ser Negro, nos termos da seleção que foi praticada na UnB, foi para um segundo lugar, quando deveria estar em primeiro plano.

Tal constatação nos leva de volta à questão: por que pretos e pardos neste momento? Por que não apenas negro, quando toda a discussão em torno das cotas raciais e das políticas de inclusão foi feita a partir da categoria Negro? Como se quis e se quer implementar esse tipo de política a partir das categorias do IBGE?

Carvalho cita rapidamente a publicação realizada por Maio e Santos (2005: 181-214) a partir de uma crítica à banca de verificação da UnB. Vários intelectuais foram convidados por esses editores para produzir um artigo a partir de um texto deles, incluindo aí ele mesmo e Rita Segato. Há posições pró e contra, algumas um tanto esdrúxulas, mas vale a pena nos determos nas considerações de Márcia Lima, negra, professora de Sociologia da USP. Ela questiona porque o "ônus" da discriminação racial, que a política de cotas deveria reparar, se transformou num "bônus", numa espécie de privilégio, cuja concessão precisa ser verificada. Há muita coisa importante nas suas considerações sobre o texto-base dos editores. Unicamente para ela, na coletânea, a existência de uma banca de verificação também despolitiza a categoria Negro que deveria ajudar a promover, numa situação na qual a Universidade acaba se reapropriando das próprias categorias que se propõe a combater, no caso a noção de raça como categoria "científica" e verificável e não como a categoria política do Movimento Negro. A(s) universidade $(\mathrm{s})$ acaba $(\mathrm{m})$ propondo um critério de classificação racial aos candidatos negros, no caso o do IBGE, sem que se tenha uma justificativa satisfatória para isso. Ela sugere que se estava tentando dar uma aparência de objetividade ao processo, quando, na prática, os problemas principais destas políticas, como a permanência dos estudantes na Universidade, permaneciam em aberto. Políticas de cotas se transformaram em sinônimo de ações afirmativas, quando são coisas diferentes, também sem muita discussão (Lima 2005: 258-261).

O que acabamos percebendo, também a partir da experiência da UFPR, é que os propósitos iniciais destas políticas foram profundamente reorientados logo no início da sua aplicação, o que é algo que precisa ser muito bem discutido a partir da memória dos envolvidos nesta primeira fase e da documentação produzida.

De alguma maneira, a necessidade de se trazer um sistema classificatório "oficial" e objetivo foi colocada por estas políticas e temos que aprofundar esta discussão. Voltemos a José Jorge de Carvalho e suas críticas ao uso das noções de Preto e Pardo. Como ele mesmo discute noutro momento de sua coletânea de artigos, para a UnB, haveria uma diferença entre os pardos do Censo e os pardos das Cotas. No início no século XXI, a UnB era uma universidade com um contingente de alunos marcadamente branco, em relação a outras universidades do País, mas, se o Distrito Federal possuía e possui um perfil 
étnico-racial característico, quase uma síntese do país, com 50\% de pardos, esse perfil se distribui pelos seus cursos de maneira muito desigual.

Ao se perguntar "Quem são os pardos das cotas" Carvalho chama a atenção para como as categorias do IBGE foram trazidas para a discussão das cotas raciais. Há uma tendência a se pensar relações raciais no Brasil em termos de relações entre brancos, pretos e pardos sob um único ponto de vista, através de um continumm de cor no qual o preto é mais discriminado do que o pardo pelo branco. Por outro lado, há uma polarização entre os privilégios da população branca frente às desvantagens dos pretos e pardos, enquanto não brancos. Esta distinção, formulada por Carlos Hasenbalg e Nelson Valle Silva, na segunda metade dos anos 70, passou a informar a categoria negro, fazendo com que os pardos sejam vistos sempre junto com os pretos em oposição aos brancos. $\mathrm{O}$ problema é que tal distinção pode fazer sentido em algumas regiões do Brasil, mas não faz sentido em todas. Pardo, em vários locais, principalmente no interior do país, pode designar pessoas que não são brancas nem pretas, não necessariamente sofrem algum tipo de discriminação racial e têm ou tiveram, historicamente, opções de ascensão social disponíveis, como migrar para o Distrito Federal e para as regióes de fronteira que se abriram após a sua construção (Carvalho 2005:75). ${ }^{4}$

Isso faz com que haja uma classe média parda, que não sofre os problemas da população negra que se quer e se quis atingir com os programas de cotas, obrigando a que seja realizada uma distinção entre pardos brancos e pardos negros, que era exatamente o que eu via a banca da UFPR fazer quando se deparava com os casos inclassificáveis. Quando aparecia uma pessoa realmente Branca querendo fraudar o processo, se declarando "parda”, ela era facilmente eliminada, não havia o que questionar. Complicado era distinguir, dentro dos autodeclarados pardos, aqueles que poderiam ser percebidos como pardos brancos ou pardos negros. Em alguns casos, nem isso era possível, devido aos resultados impensáveis da mestiçagem. Havia também os casos de pessoas com origens japonesas ou árabes que causavam outro tipo de dificuldade.

Um problema que surge na releitura das questões de Carvalho, mais de doze anos depois, é que ele escrevera parecendo acreditar que as pessoas brancas, pretas e pardas realmente existiam enquanto tal, ou seja, que se autoidentifiquem nestes termos entre si, embora mostre em vários momentos que as fronteiras entre estas categorias são bastante fluidas e em permanente negociação. O que chama a atenção, em primeiro lugar, é que estas categorias parecem fazer sentido no país como um todo, embora designando pessoas com perfis bastante diferentes conforme as regiões e, nestas, o contexto local de classe, status e ocupação profissional. Vale a pena conferir essa questão com outros autores.

Uma discussão muito relevante para este ponto pode ser encontrada no artigo de Graziella Moraes Silva e Luciana de Souza Leão sobre um survey realizado com "brasileiros pardos". Há muita discussão que pode ser aproveitada para pensarmos melhor a questão de políticas públicas para pretos e

\footnotetext{
4 Quero crer que estas definições, oriundas destes estudos dos anos 70, precisam ser revistas. Parece que serviram basicamente para constatar que os negros, entendidos como pardos e pretos, eram mais pobres do que os brancos e tinham menos acesso a certos serviços e oportunidades. Ao final, parecem ter servido para dar uma base "científica" à ideia de que os negros são pobres e por isso precisam de políticas públicas para saírem da pobreza, ideia que informa não apenas as políticas raciais das IFES mas todo o debate em torno delas, tanto os argumentos prós como os contrários. Vistas a partir de hoje, e da necessidade de uma etnificação melhor definida destas categorias "étnico-raciais", podem não ser muito úteis. Parece que terminam por redefinir o "Negro" das três raças, que é uma categoria da Nação, não de grupos étnicos empíricos.
} 
pardos, tentando entender, afinal, quem são estes pardos? As autoras procuram relacionar a definição de quem é negro no Brasil com o peso que a discriminação racial tem como explicação para as desigualdades raciais. Como se mede a discriminação e como se define quem é negro? Dependendo dos critérios utilizados temos resultados muito distintos (Silva \& Leão 2012: 117-255).

Seu artigo apresenta um histórico dos censos sobre raça no Brasil, permitindo perceber algumas coisas que vale a pena destacar. "Pardo" é inicialmente uma categoria de uso comum no Brasil escravocrata, servindo para designar negros livres, a expressão completa seria "pardo livre", o que reforça a ideia de que a categoria tem um caráter desestigmatizante, em relação aos estigmas do Negro e do Preto. No período republicano a categoria Pardo passa a ser utilizada, desde 1940, para agrupar todos aqueles que não são "brancos, pretos ou amarelos". Os índios, os caboclos, os mulatos, os morenos, todos passam a ser definidos como pardos, em oposição às três primeiras categorias, que parecem melhor definidoras com relação à cor e raça do que esta noção genérica de Pardo. Os números percentuais desta categoria crescem nos Censos subsequentes, ao mesmo tempo em que o Mestiço passa a ser visto como o tipo brasileiro por excelência. Deste breve histórico já podemos destacar uma questão. O Pardo é apenas o mulato, entendido como um negro misturado, ou é qualquer tipo de mestiço, sendo que, neste segundo caso, nem todos realmente se veriam como negros, podendo se perceber de outras maneiras?

A pesquisa em questão se centra na autorrepresentação de pessoas pardas, e no que elas têm a dizer sobre negritude e discriminação. Foram entrevistadas cerca de 160 pessoas na cidade do Rio de Janeiro, e a maneira como estes entrevistados foram selecionados é relevante. Selecionando pessoas de classe média, com formação superior, e da classe trabalhadora, com ensino médio e empregos formais, trabalharam a partir de gerências de recursos humanos de grandes empresas e de empresas de marketing, que operam com heteroclassificação de funcionários. A partir de um pequeno grupo inicial de selecionados, a pesquisa seguiu através das indicações destes para novos entrevistados. De qualquer modo, a pesquisa trabalhou com "profissionais negros", definidos a partir da sua relação com o mercado de trabalho.

"Ser negro" apareceu como algo muito relacionado a ser discriminado racialmente, sendo que os pretos se declaram mais discriminados do que os pardos. Com relação a estes, a pesquisa acabou trabalhando com três categorias, negros-pardos, pardos-negros e pardos-pardos. Os primeiros são aqueles que se autoidentificam como negros, mas se classificam como pardos a partir das categorias do IBGE, geralmente de classe média. No segundo grupo, os que se autoidentificam como pardos e como negros, geralmente pessoas mais jovens, mais influenciadas pelas discussões recentes sobre a negritude no Brasil. No terceiro grupo, pessoas que se veem como mestiças, seja pela ascendência seja pela classificação dos documentos oficiais, e para as quais se identificar como Negro pode surgir como algo mais complicado, já que podem se definir de outras maneiras.

Todas essas definições podiam ser encontradas nas bancas da UFPR. Os pretos, em primeiro lugar, sempre fáceis de confirmar a autoclassificação. Aqueles que se definem como pardos, pela classificação do IBGE, e se veem como negros, de alguma maneira. E aqueles que se veem como mestiços e como pardos, geralmente em função das relações de parentesco, ou seja, porque os pais são de tipos raciais distintos. As dificuldades na verificação da autoidentificação apareciam aqui, onde surgiam os 
tipos inclassificáveis à heteroclassificação da banca, num desgastante esforço de produzir uma observação da raça dos candidatos que pudesse ser "objetiva”.

A leitura da discussão do artigo de Silva \& Leão (2012) permite perceber como as categorias do IBGE têm um peso na autoidentificação dessas pessoas, mas não são o único definidor. É mais um elemento que conta nos diversos processos de negociação de identidades pessoais no Brasil a partir da dimensão étnico-racial, seja no ambiente familiar, seja diante do Estado, seja no mercado de trabalho. No caso das bancas da UFPR, e nos atuais processos de acesso à Universidade pública, se está num momento anterior à entrada no mercado de trabalho, de tal forma que essas análises podem se complementar.

O processo de aprovação do Plano de Metas de Inclusão Racial e Social da UFPR foi resultado de uma negociação difícil, que pode ser acompanhada pela antropóloga do Departamento de Antropologia da UFPR Ciméa Bevilaqua. Em artigo raro dentro deste debate, conseguiu etnografar o processo decisório dentro das reuniões do Conselho Universitário que aprovariam o Programa. De modo comparável ao debate e às polêmicas em torno das cotas raciais, os votos obedeciam a toda uma ordem de interesses e posições políticas internas ao campo político universitário, em primeiro lugar. $\mathrm{O}$ movimento negro curitibano, por sua vez, principalmente através do Fórum dos Professores Negros, fez uma campanha intensiva pela aprovação do Programa, que acabou sendo aprovado por diferença de um voto.

Bevilaqua chama a atenção ao fato de que o Programa teve problemas em sua implementação desde o primeiro vestibular. Nem todas as vagas foram preenchidas e houve um número elevado de pessoas que se declararam negras e pardas, mas não tiveram sua autodeclaração validada. A maioria entrou com recurso jurídico e teve sua matrícula garantida, sendo aprovados em segunda instância (Bevilaqua 2005:214-15). A dificuldade em classificar e distinguir o branco do negro surgiria, no caso de estudantes cuja aparência é resultado de uma forte mestiçagem familiar, constituindo uma ideia de família mestiça e não de família negra.

Nos anos seguintes, como eu pude constatar, esse desafio continuou. Grosso modo, é estabelecida uma linha de corte, dentro da categoria pardo, entre pessoas de um tipo "moreno brasileiro", que, na região sul, podem ser definidas como negras pelos habitantes brancos de origem européia, mas, se vistas como mestiças pelos representantes do Movimento Negro, nem sempre são vistas como negras, por esses mesmos representantes. Em geral, essas pessoas têm apenas um avô ou avó negro(a), como declaram. Por outro lado, todas as pessoas negras, de pele clara, mestiços com ascendência negra evidente, eram incluídas. Em geral, essas pessoas têm ou o pai ou a mãe negro(a). Em jogo, num processo seletivo cujos candidatos são, por ordem, da região metropolitana de Curitiba, do interior do estado do Paraná, do interior dos estados de São Paulo e de Santa Catarina e, residualmente, de outras regiões do país, a distinção - e distância - entre o "branco europeu" e o "branco brasileiro" tem efeitos na definição de preto e pardo. Pardos podem ser brancos brasileiros aos olhos dos pretos e negros aos olhos dos europeus. O processo de validação da autoidentificação étnico-racial termina sendo um esforço de estabelecer uma linha de corte dentro desta categoria pardo - entre quem pode ser percebido como negro ou não, com essa especificidade, o não negro é um branco brasileiro, sempre, ou um mestiço cuja cor parda não 
é redefinida nem como branca nem como negra, dentro das indefinições características desta categoria, tão bem apontadas por Lilia Moritz Schwarcz (1998:225) e por João Pacheco de Oliveira (1999:124).

Em artigo publicado na coletânea RAÇA, novas perspectivas antropológicas ${ }^{5}$, Marcelo Paixão e Luiz Carvano também abordaram este tema (Paixão \& Carvano 2008: 25-60). Sem querer entrar nas considerações iniciais dos autores sobre o conceito de Raça e seus diversos usos e definições ao longo da história em diversos contextos nacionais e internacionais, vale a pena discutir as relações entre mestiçagem e as terminologias de autoidentificação, que, conforme eles afirmam, impede que se queira falar apenas em termos de brancos e negros no Brasil. Embora uma série de estudos apontem para a existência de diversos termos classificatórios em diversos locais do país, desde os estudos da PNAD/ IBGE de 1976, a maioria da população se representa a partir das categorias "oficiais": branca, preta, amarela e parda, mais as seguintes categorias: clara, morena clara e morena, categoria que recebia um terço das respostas. Tal constatação nos leva a uma discussão sobre as categorias "moreno" e "pardo" enquanto sinônimas. Outros estudos apontam que, quando induzidos, a maioria dos morenos se reclassifica enquanto pardos, alguns como brancos e muito poucos como pretos. Há um problema aqui que os autores terminam formulando muito bem nos seguintes termos:

\begin{abstract}
"Quanto à cor parda, o problema é que esse termo acaba agregando em sua rubrica pessoas de origens distintas (africanas, indígenas, caboclos, certos tipos de árabes, etc). Dentro da mesma lógica, existem ressalvas quanto à junção de pretos e pardos em uma única categoria denominada negra. Refletindo sobre esta segunda objeção, de fato, somos obrigados a constatar que, na ausência de um campo, no questionário das pesquisas demográficas, que remeta às origens étnico-raciais dos indivíduos, tal lacuna não terá como ser enfrentada” (Paixão \& Carvano 2008:48/49).
\end{abstract}

Por outro lado, os autores também insistem em que os indicadores sociais tendem a aproximar pretos e pardos como um grupo comum, diferente dos brancos, independentemente das questões de autopercepção de cada um. Esta afirmação já foi bastante comprovada estatisticamente mas, vista desta forma, coloca problemas quando estamos tratando de aplicar uma política pública que define o beneficiário da mesma a partir de seu fenótipo enquanto Negro, entendido como alguém que se define enquanto preto ou pardo. Um fenótipo que precisa ser confirmado por uma heteroclassificação. Essa raça observada toma o lugar de uma definição política de Ser Negro, enquanto membro de uma categoria coletiva definida por outros pertencimentos, como laços familiares e comunitários.

A partir da UFPR é possível dizer que os candidatos pretos se veem e são vistos facilmente como Negros e que estas categorias tendem a ser utilizadas como sinônimos, tanto por esses candidatos como também pelos agentes estatais e do Movimento Negro, responsáveis por essas políticas. O mesmo não se pode dizer com relação aos pardos, que, se são a maioria dos candidatos, precisam ser reclassificados

5 Publicação da ABA - Associação Brasileira de Antropologia em coedição com a UFBA. Disponível em https://repositorio.ufba.br/ri/ bitstream/ri/8749/1/_RAC\%CC\%A7A_2ed_RI.pdf_.pdf 
de alguma maneira. Basicamente as bancas, seja na UFPR, na UnB, na UEMS ou na UEPG ${ }^{6}$, parecem sempre ter agido promovendo esta reclassificação.

Tal constatação nos remete a outra dimensão da questão, o fato de que estamos lidando com políticas públicas aplicadas e promovidas a partir do Estado Nacional Brasileiro, que atua a partir de noções sobre a composição cultural, étnica e racial do país que ele mesmo produz e promove, geralmente de formas um tanto divergentes, atendendo a interesses diversos em jogo.

Antonio Sérgio Alfredo Guimarães chama a atenção, em seu artigo publicado na coletânea Raça, sobre como o pensamento sobre raça, nas ciências sociais brasileiras, sempre esteve intimamente ligado à ideologia da Nação brasileira. A ideia de Nação passa a ser o discurso da Ciência, e provavelmente continua sendo, quero crer, fato que precisa ser devidamente problematizado para uma melhor compreensão destas questões. (Guimarães 2008: 63-80).

Guimarães retoma a questão de como o Movimento Negro brasileiro passa a utilizar uma série de estudos estatísticos para construir a noção de Negro a partir da união de pardos e pretos, uma vez que seus indicadores sociais são convergentes. O problema, segundo ele, é que este conceito não é nem mais somente analítico, dentro de um quadro científico "objetivo", ou somente nativo, dentro dos limites da ação política do MNU. Um conceito nativo cada vez mais politizado frente às demandas por políticas públicas, que irá necessitar de um suporte, seja este estatal burocrático, ou mesmo "científico". As categorias do IBGE parecem dar conta dessa ambiguidade. Esta noção se universalizou no discurso político do Brasil pós-ditadura e suas ambiguidades se tornam um novo objeto, que é o que estou tentando pensar a partir das bancas de verificação da autodeclaração no vestibular da UFPR.

Como Guimarães afirma, ao propor um conceito sociológico de Raça, o que está em jogo no Brasil em primeiro lugar não é raça, mas Cor. Negros, mulatos e pardos são categorias orientadas por noções sobre Raças, um tipo de signo que nomeia diferenças sociais, que na prática não existem como algo dado.

O que Guimarães apresenta, ao finalizar o seu artigo, é muito relevante para esta discussão: é exatamente uma problematização do exercício classificatório de raças, cores e tipos étnico-raciais, como eu via acontecer na prática nas bancas da UFPR. Basicamente, o que ele sugere, é que se realizem entrevistas nas quais a autodeclaração possa ser conferida, a partir de fotografias, de perguntas abertas e fechadas sobre raça e cor. Na prática, nas bancas da UFPR era isso o que acontecia, quando se estava diante dos casos inclassificáveis. Por mais que os militantes do Movimento Negro Paranaense gostassem de enfatizar que o que estava em jogo era o fenótipo, a banca estava lá para constatar que a pessoa era Negra - e não branca - e os casos complicados exigiam que se fizessem entrevistas. Perguntas sobre como a pessoa se autoidentificava, origens familiares, casos de racismo que teria sofrido, era assim que

6 Ver a dissertação de Marielli Ramos Pinheiro (2014) sobre a banca de verificação da autodeclaração racial na Universidade Estadual de Ponta Grossa (PR). 
se buscava reclassificar as pessoas. Esta prática se impunha, não tinha como não fazer. Nos recursos, era comum os candidatos trazerem fotos de família, quando não os próprios pais. ${ }^{7}$

\section{"Participação observante”}

Uma discussão muito apropriada para esta problematização antropológica é a que Letícia Carvalho Ferreira apresenta em uma coletânea recente sobre pesquisas com políticas públicas e as relações de poder a elas relacionadas. Investigando o caso de desaparecidos, a partir da polícia carioca, deparou-se com uma distinção, realizada pelos seus agentes, entre problemas de polícia e problemas de família. Para os investigadores policiais a maioria dos casos de desaparecidos não eram problemas da polícia, mas sim problemas das famílias. Através de uma série de situações institucionais chegaram a uma tipologia de seis tipos de desaparecimentos, nos quais somente dois tipos deveriam ser alvo de investigação policial, os sequestros e os desaparecimentos enigmáticos de pessoas. Os outros eram casos de família. Na condição de uma pesquisadora que realiza seu doutorado em antropologia, mas que é incorporada à rede nacional que pensa essa questão, a autora realiza uma reflexão interessante sobre o lugar do antropólogo diante dessas necessidades de classificar, produzidas pela aplicação de políticas públicas do Estado ( Ferreira 2014: 127-149).

Letícia Ferreira revela seu incômodo com a participação neste processo já que, como lidar, como antropóloga, com a produção de categorias fechadas e fronteiras rígidas entre tipos, alimentando recursos às classificações e taxonomias incontornáveis, mas que podem gerar processos de exclusão, já que se trata de processos decisórios envolvendo o destino de pessoas. Ela irá mostrar que tais sistemas de classificação e de aplicação das políticas que os engendram e deles necessitam surgem a partir de muitas discussões, reuniões e outras situações tipicamente burocráticas, que precisam ser analisadas nestes termos. Dois eixos de reflexão são propostos por ela. A discussão sobre uma antropologia dos sistemas burocráticos, realizada por Michael Herzfeld, e algumas inquietações metodológicas de pesquisadores do LACED/MN, como Antonio Carlos de Souza Lima e João Pacheco de Oliveira.

Herzfeld sugere uma provocativa aproximação entre a autoridade antropológica e a autoridade etnográfica, a ser conferida em situações nas quais o antropólogo dialoga com burocratas ou se aproxima de se transformar em um. Para ele, as burocracias estatais não são mais racionais e menos simbólicas do que o resto da sociedade, como algumas pessoas podem pensar, mas se caracterizam por um constante apagar dos mecanismos que sustentam o seu próprio poder, um objeto que pode ser etnografado por quem mergulhar nos seus trâmites. O próprio nome do seu trabalho, A produção social da indiferença, muito diz sobre as dificuldades com a instalação da política de cotas na UFPR, e seguramente no resto do país. Há uma reconhecida indiferença dos setores universitários frente a estas políticas, a

\footnotetext{
7 Em 01/08/2017 a Resolução n. ${ }^{\circ}$ 20/17 do CEPE- Conselho de Ensino, Pesquisa e Extensão da UFPR terminou definindo que:

"Art. $4^{\circ}$ - Para validar o termo de autodeclaração de candidatos às vagas reservadas aos candidatos PP será considerado única e exclusivamente o fenótipo negro como base para análise e validação, excluídas as considerações sobre a ascendência.

$\$ 1^{\circ}$ Entende-se por fenótipo o conjunto de características físicas do indivíduo, predominantemente a cor da pele, a textura do cabelo e os aspectos faciais, que, combinados ou não, permitirão validar ou invalidar a autodeclaração.

$\$ 2^{\circ}$ As características fenotípicas descritas no parágrafo anterior são as que possibilitam, nas relações sociais, o reconhecimento do indivíduo como preto ou pardo."
} 
maioria das pessoas envolvidas pouco conhece da legislação, das discussões e dos objetivos das mesmas, o que obriga que certas questões tenham que estar sempre voltando à tona enquanto outras não saiam do lugar. Ao mesmo tempo, todos parecem operar como se os conceitos e princípios em questão fossem autoevidentes, quando não são. $\mathrm{O}$ resultado é que alguns temas são discutidos, como o atraso causado pelo registro dos cotistas raciais diante do registro acadêmico como um todo, fosse pela necessidade da banca e dos recursos contra ela, fosse pelo atendimento diferenciado pelos membros do NEAB aos estudantes aprovados. Enquanto isso, a necessidade de uma recepção diferenciada para os calouros negros ficava como um tema secundário e pouco discutido.

Outro autor a discutir Herzfeld e a discutir a implantação de programas de cotas nas universidades públicas é Marcio Goldman, antropólogo do Museu Nacional/UFRJ. Resenhando outro livro deste autor ${ }^{8}$, enfatiza como a maioria das nossas pesquisas acontece dentro de Estados Nacionais, de diversas maneiras, de tal forma que antropologias dos estados nacionais - e não apenas nos estados nacionais - surgem como um objeto antropológico a ser devidamente explorado. O Estado e suas instituições, seus agentes e suas estratégias operam com todos os materiais que os antropólogos trabalham, como crenças e mitos, identidades e estereótipos, só que no sentido de essencializá-los. O Estado tende a reduzir a diversidade cultural em todas as suas manifestações, o objeto da antropologia, numa série de identidades pausterizadas que tendem a dialogar mal entre si, já que se definem primeiramente nesta relação com o Estado, disputando reconhecimento. Essa característica da relação do estado com a cultura coloca um sério desafio aos antropólogos, ao trabalharem com a gênese contemporânea de identidades, com as reivindicações por políticas públicas diferenciadas e com a maneira como estas políticas públicas são pensadas e implementadas (Goldman 1998: 150-153).

Refletindo, com Gabriel Banaggia, sobre o processo de implantação de cotas no Programa de Pós-graduação em Antropologia Social do Museu Nacional, Goldman aponta para questões que nos interessam aqui. Se forem feitas críticas com base "científica" aos programas de cotas, que noção de ciência está presente nestas críticas? Se a ideia de Raça deixou, há um bom tempo, o campo da ciência em direção a certo senso comum, com a sua reapropriação, por discussões políticas e acadêmicas, enquanto políticas raciais e processos de racialização, a ideia de raça e tudo o que se associa a ela, deixa o campo da discussão sobre ideias e preconceitos para o campo das políticas públicas e da política em geral. De que noções de Política estão falando agora? Goldman afirma que antes de ser um preconceito ou uma ideologia, o racismo é uma prática de poder (Goldman \& Banaggia 2017: 16-34).

Aqui, as questões de Herzfeld fazem muito sentido, para situarmos melhor tanto os dilemas na definição da categoria Negros, diante dos Pretos e Pardos do IBGE, quanto a enorme confusão que se formou no meio acadêmico brasileiro, não somente antropológico, com o surgimento das políticas de cotas raciais. Goldman recupera o debate publicado em Horizontes Antropológicos (11(23), 2005) a partir da crítica de Ana Lúcia Valente, que se referiu ao mesmo enquanto uma "má vontade antropológica" frente a essas políticas por parte de diversos intelectuais manifestando a sua indiferença e desinteresse frente às mesmas.

8 Cultural Intimacy: Social poetics in the Nation-state. New York/London: Routledge, 1996. Também em tradução portuguesa: Intimidade Cultural: poética social no Estado Nação. Perspectivas do Homem, 57. Coimbra: Edições 70. 
A ação dos debates estatais, junto aos movimentos sociais, atuou em dois sentidos. Em primeiro lugar, numa tentativa de resguardar uma noção de Identidade Nacional única e universal, no modelo clássico do Estado Nacional iluminista, que é o que a maioria dos intelectuais contrários às cotas procurava defender. Noutro sentido, a força das reivindicações por direitos a sua própria diferença, nada universalizáveis, a princípio, postuladas por diversos movimentos sociais, tendem a acabar pausterizados numa nova forma jurídica e política genérica, que, se não atende a essas reivindicações, permite que o sistema jurídico estatal possa pensá-las e operar suas políticas para atendê-las. A necessidade da utilização das categorias do Censo do IBGE, o "PPI", e o preço que se paga por esse uso, parecem fazer sentido quanto vistos por este prisma. O que novamente nos faz retomar o eixo desta discussão, como lidar com esse tipo de questão enquanto um antropólogo que se envolve com esse tipo de política pública afirmativa e inclusiva?

Vale a pena retornar as discussões de Ana Lúcia Valente, que têm como ponto de partida a banca de validação da UnB e as preocupações do Comitê de Relações Étnicas e Raciais da ABA, que se manifestou em nota contra esta banca, em nome de um "constrangimento" aos candidatos. Na sua resposta ao CRER, Valente mostra que os únicos constrangidos, à época, eram aqueles que deveriam ser constrangidos mesmo, ou seja, aqueles que a banca tinha por objetivo eliminar, os não negros. Sua discussão também parte de que tais bancas são um momento de negociação de identidades étnicas que, como eu sempre defendo, tais políticas induzem e exigem e, portanto, onde estaria o problema de um ponto de vista antropológico? Qualquer pesquisador que se dispusesse a participar de tais bancas, como eu fiz, terminaria percebendo essa dimensão e sua importância para a implementação desse tipo de política (Valente 2006: 84-103).

Valente também teve acesso aos dados da banca da UnB e se deparou com a seguinte questão: "A análise dos recursos das candidaturas não-homologadas que realizei em duas oportunidades sinalizam duas fortes impressões. A primeira delas diz respeito ao único argumento utilizado: o fato de os candidatos serem "pardos". Por vezes a afirmação foi acompanhada da justificativa de que "se as cotas fossem apenas para os negros", não teriam feito a inscrição no processo. Argumento que além de justo foi legitimado pelo edital, posto que a política de cotas da UnB tem como público-alvo negros e pardos. Em decorrência disso, o foco de atenção deveria ser o edital, onde as regras são estabelecidas" (Valente 2006:99).

Valente também propôs que as cotas raciais deveriam ser para Negros, e não para pretos e pardos, não sem ressaltar as dificuldades na definição desses negros para os fins desse tipo de política. De um lado, sempre há o risco desse tipo de política ser considerada uma ameaça à "integração nacional", ao espírito nacional, sincrético e mestiço; de outro lado, a mestiçagem de fato gera uma diversidade difícil de classificar.

Creio que, neste ponto, podemos dizer que as classificações devem atender não a critérios "objetivos" e "científicos" mas a critérios devidamente explicitados, que levem em conta a tensão que Guimarães (op.cit.) ressaltou entre os conceitos analíticos, das ciências sociais, e os conceitos nativos,

9 PPI: pretos, pardos e indígenas, como categorias alvo das políticas afirmativas nas universidades federais e em outras instâncias do governo federal. 
dos movimentos sociais, pois aqui, de fato, surgem confusões de significados. Infelizmente, o que tem sido possível constatar é que a implantação do programa de cotas raciais na UFPR se deu e continua se dando em uma discussão fortemente marcada mais por estereótipos do senso comum, em torno da identidade nacional brasileira, do que por uma reflexão conceitual atualizada, por parte dos agentes envolvidos. Tal tema também não é novo, todavia.

Giralda Seyferth já havia discutido que, diante do tema das relações raciais no Brasil, os argumentos científicos sempre estiveram próximos dos estereótipos do senso comum sobre o tema da mestiçagem, e vice-versa, verificando-se o uso de linguagem científica para reforçar noções estereotipadas. Se é possível ver no racismo o predomínio de doutrinas da superioridade europeia por sobre a argumentação científica a respeito de Raça, cultura, etnia, ideologia, etc., não devemos perder de vista que se está - desde o século XIX, pelo menos - lidando com a construção de lógicas classificatórias, que caracterizam a formação dos horizontes culturais da nação brasileira, dentro dos quais os usos e definições de conceitos fundamentais para a reflexão antropológica são reapropriados e redefinidos.

Giralda Seyferth também já discutira como a questão da mestiçagem na identidade brasileira envolve a operacionalização de uma lógica classificatória e dos valores que definem esta classificação. O debate racial brasileiro, a partir do século XIX, produziria o ideal de um "mestiço superior". Negros, índios e mestiços eram raças inferiores, incapazes de competir livremente no mercado de trabalho capitalista moderno, por um lado; mas, aqueles que se branqueassem, através da mestiçagem com os europeus, estariam numa situação melhor. As definições altamente estereotipadas do "mestiço" e da "mestiçagem" combinam qualidades dos brancos e defeitos dos negros e índios, numa lógica na qual categorias definidoras de raça, cor, tendem a ser depreciativas, subordinadas a uma estética branca, presa a um ideal de civilização moderna. A famosa estética da morenidade, popular até hoje, consiste num elogio do mestiço superior, enquanto os traços negroides continuam a desqualificar o seu portador, mesmo quando a cor da pele é celebrada. Não é difícil perceber, assim, que a necessidade de se situar diante das classificações raciais vigentes no Brasil torna-se um desafio para os candidatos às cotas raciais e para os demais envolvidos no processo (Seyfert 1995:175).

Disto tudo deriva um problema mais amplo. Como propor um novo lugar social para os negros, dentro da sociedade brasileira, sem alterar o sistema classificatório vigente como um todo, se ele permanece, inclusive, implícito para a maioria dos cidadãos, dentro desse processo? Ao dar novos significados ao ser negro no Brasil, as manifestações culturais e políticas da negritude induzem, até certo ponto, uma redefinição do sistema como um todo. A enorme polêmica gerada pelas cotas raciais nas Universidades e o sentimento de ameaça de "divisão" do País podem ser vistos também como reações a essas consequências de todo este processo gerado a partir e em torno das atuais políticas culturais da negritude no Brasil.

Até que ponto a política de cotas raciais rompe com a lógica do mestiço superior ou até que ponto não se legitima a partir dela? Espera-se que o cotista formado seja um negro com formação superior, este continuará sendo um "pardo superior" e a política de cotas poderá contribuir para uma substituição da noção de Mestiço, entendido enquanto “pessoa de cor”, pela noção de Negro? 
Graziella Silva \& Luciana Leão (op.cit) partem de um questionamento a respeito da pouca identificação dos pardos enquanto negros. Já que Ser Negro seria entendido apenas como aqueles que sofrem discriminação, tal argumento não seria evidência de uma falta de consciência racial por parte dos pardos? É um argumento bastante comum no ambiente dos movimentos negros, uma ideia de que "o Pardo é o Negro que não quer ser negro”. Elas discutem, a partir dos seus dados, numa outra direção. Ser Pardo, podendo significar muitas coisas ou coisa alguma, é uma identidade cujos significados precisam ser mais bem explorados. Como na UFPR, os interlocutores enfatizam muito as diversas origens familiares que compõem o universo identitário disponível para eles. Outra questão que as autoras apontam é que, para muitos dos seus entrevistados, ser Negro aparece como uma opção política consciente, enquanto o Pardo, enquanto resultado de uma união mestiça, de ser membro de uma família mestiça, surge quase como um dado objetivo. Ou seja, as duas categorias definem dimensões distintas da identidade dessas pessoas de uma forma não contraditória, mas sem serem sinônimas. Resumindo, podemos dizer que uma pessoa não é Negra por ser Parda, pois ser Negro e ser Pardo significam coisas distintas para essas pessoas.

Eu prefiro propor que talvez seja a hora de estranharmos um pouco essa dificuldade em classificar a diversidade da população de cor para definir quem são os negros no Brasil. O problema pode estar em uma questão de perspectiva. Vários autores já chamaram a atenção para como, desde a década de 70, os movimentos negros procuram repensar a 'mestiçagem brasileira' e o seu lugar nela. Talvez valha mais a pena perceber melhor que estamos assistindo à construção de uma nova noção de Negro Brasileiro, que ainda não está plenamente definida, ainda não constitui um novo imaginário nacional, mas que será definida através dessas políticas e dos debates que geram, desde que estes debates sejam levados a sério. Aqui, o papel do antropólogo como um mediador de diferenças e um contextualizador de categorias que informam identidades se faz necessário, assim como uma discussão sobre que tipo de antropologia se fazer nestes casos.

O ponto a ser considerado é que a política de cotas raciais, ao criar um espaço legítimo e desejável de "ser negro", estabelece uma nova fronteira étnica, uma zona de negociação de identidades étnicas, estabelecendo um terreno próprio de etnicidade que não foi devidamente reconhecido e discutido pelos agentes envolvidos. As discussões principais têm sido de outra ordem. Temos que reconhecer melhor a existência desses dois aspectos: novas relações interétnicas foram geradas a partir da lei de cotas e tanto estas relações, assim como os temas em discussão, constituem este novo campo de relações interétnicas com suas novas questões.

Discutindo sobre a antropologia voltada para as políticas públicas, mas não apenas, João Pacheco de Oliveira discorre sobre um certo "mal-estar" na antropologia, causado por, talvez, um excesso de envolvimento de alguns pesquisadores e suas pesquisas diante da vida nativa que deveriam, em tese, apenas observar. Ele pergunta se o diálogo com os atores sociais não estaria afastando essas pesquisas de sua necessária objetividade e conduzindo-as para questões que não teria condições de resolver.

Sua pergunta parece resumir muito do que vimos discutindo neste artigo, assim como a preocupação de diversos dos autores acima citados. Uma das questões a que Oliveira imediatamente chama a atenção são os novos tipos de produção antropológica que resultam destas empreitadas. Não apenas te- 
ses e artigos, mas relatórios, laudos e materiais voltados para certos tipos de campanhas e mobilizações, que passam a fazer parte de um novo fazer antropológico.

O "mal-estar" seria gerado por um descompasso entre a imagem da antropologia que se ensina e a antropologia que se faz na prática, que é bastante real nos cursos de antropologia, seja na graduação sejam nos cursos de pós-graduação. Muito deste mal-estar foi causado por um movimento interno da própria disciplina, de procurar novos campos de pesquisa e novas formas de pesquisar, utilizando a observação participante, a análise qualitativa e o esforço de aprender uma cultura distinta da sua, que puderam, com sucesso, ser aplicados a situações mais complexas e mais próximas dos pesquisadores (Oliveira 2009: 2-27).

Por outro lado, o mundo mudou e as comunidades anteriormente estudadas pelos antropólogos também. As pesquisas precisam ser devidamente negociadas com as comunidades pesquisadas, fazendo com que o interesse acadêmico tenha que ser compartilhado com demandas propriamente políticas desses interlocutores. Antropólogos não podem pretender ser neutros diante das situações políticas de seus campos, tampouco se tornam especialistas no estilo de vida de seus interlocutores, com uma autoridade "científica" reconhecida.

João Pacheco de Oliveira finaliza concluindo que estamos assistindo ao surgimento de novas maneiras de se fazer etnografia, o que é positivo para a Antropologia, desde que se entenda a abertura que a disciplina está sofrendo com o surgimento de novos métodos e objetos, sem se preocupar com a proposta de novas escolas ou novos paradigmas.

Estas questões retomam uma discussão já clássica, apresentada por Eunice Durham no início dos anos 80 , justamente quando a antropologia se abria para os novos horizontes da politização dos seus antigos interlocutores, os grupos minoritários. Perguntando se a Antropologia estava em condiçóes de responder aos desafios das transformações da sociedade brasileira, apontava uma série de novos problemas que surgiam. Um deles seria uma opção mais por uma "participação observante", na qual o envolvimento com a politização crescente dos movimentos sociais parecia querer substituir a observação sistemática do método antropológico. Sem invalidar tal inserção em campo, Durham chamava a atenção para o desafio de se pesquisar processos sociais nos quais o pesquisador também é um agente. A solução estaria em enfrentar os novos desafios epistemológicos com uma reflexão teórica e metodológica adequada, para evitar uma série de deslizes semânticos na aplicação dos conceitos sociológicos. Durham enxergava uma despolitização dos conceitos acompanhando a politização das pesquisas, que é uma questão a ser devidamente considerada, principalmente diante da possível confusão entre conceitos analíticos e nativos. Ela apontava também para o equívoco de se reduzir a análise antropológica a uma explicação de uma situação social através das categorias nativas, quando o objetivo de uma análise é explicar, através dos conceitos teóricos, as categorias nativas em seus contextos sociais. A interpretação sociológica acrescenta algo à interpretação nativa, e esse "algo" pode ser politicamente relevante, se o processo todo é bem conduzido e bem discutido (Durham 2004: 216-234).

A “participação observante" também nos remete a outras questões nesta discussão sobre as bancas de verificação da autodeclaração racial e as categorias classificatórias envolvidas no processo. Eu defendo que esta opção metodológica se impõe neste tipo de atuação de um(a) pesquisador(a) e que 
deve ser devidamente problematizada. Seria muito complicado pretender participar do processo das bancas sem ter algum envolvimento com o processo e as discussões que ele levanta, uma vez que é em torno destas discussões que os temas relevantes vêm à tona. Pretender uma postura de um "observador participante", relativamente neutro, não renderia muito. É preciso reconhecer uma experiência de participação através de uma presença participativa, o que termina produzindo um movimento entre uma observação participante, que sempre estará presente, e uma participação observante que se impõe. Aqui entra em jogo outra questão, a da autoridade etnográfica.

O tema da autoridade etnográfica gerou um grande debate desde a publicação do trabalho de James Clifford. Lido de diversas formas no Brasil, às vezes de forma pouco crítica, pode gerar alguns problemas, como ressaltou Mauro de Almeida. Num contexto onde pesquisadores e pesquisados são concidadãos e onde o resultado das pesquisas antropológicas tem efeitos sociais e políticos, questionar por demais a autoridade do etnógrafo, em sua experiência de campo e em sua reflexão teórica sobre sua experiência, em termos da "objetividade" do conhecimento produzido, não faz muito sentido. Em situações nas quais a produção antropológica serve para a defesa de interesses de grupos minoritários, em negociações complicadas com os grupos que realmente têm poder e voz frente ao Estado, a autoridade da pesquisa etnográfica e a objetividade de suas 'verdades' deve ser defendida (Almeida 2003: 9-29).

No caso que estamos tratando aqui, da classificação racial envolvida nas políticas de inclusão racial das Universidades Públicas, a "objetividade” aparece de várias formas. Em primeiro lugar, como uma espécie de necessidade de critérios objetivos para definir quem é ou não negro no país. Embora a questão, de fato, não tenha surgido a partir de uma iniciativa acadêmica, rapidamente se encaminhou para uma perspectiva antropológica, historicamente ligada a esse tipo de questão. No debate que se seguiu, dentro da antropologia, o que se viu, foi, lamentavelmente, a ausência de uma autoridade etnográfica necessária para a construção de certos argumentos, com intelectuais refletindo sobre o tema a partir de informações de terceiros, de forma bastante preconceituosa. Como perceberam Antonio Sérgio Guimarães e Flávia Rios, resenhando coletâneas sobre as cotas raciais produzidas pelo CEAO/ UFBA (Santos 2012, 2013), a oposição às cotas foi mais intensa com relação às cotas para negros, sempre com os mesmos argumentos contra as propostas de criação destes sistemas, que acabaram prevalecendo (Guimarães \& Rios2014: 251-56).

Não há muito que dizer sobre este debate, que de fato pouco diz em seus argumentos sem a devida autoridade etnográfica e teórica. O texto de Ana Luísa Valente (op.cit) continua exemplar em sua crítica a estas atitudes. $\mathrm{O}$ que há de melhor a ser feito é pesquisar e analisar os contextos nos quais esses debates foram produzidos e os seus efeitos para todos os envolvidos.

Se James Clifford, ao discutir autoridade etnográfica, estava criticando o projeto intelectual de uma observação e análise da vida nativa para uma descrição "a mais fiel possível” e propondo uma etnografia interpretativa na qual teoria e dados continuam interligados, tal projeto antropológico, devidamente atualizado pelos questões pós-modernas, é útil a essas discussões que políticas afirmativas, cotas raciais e bancas de verificação de autodeclaração colocam (Clifford 1998: 17- 62).

Ainda seguindo suas considerações, não faz sentido perseguir uma objetividade e uma neutralidade inexistentes. Todo o processo de negociação étnica que as bancas, em particular, e as políticas 
afirmativas, em geral, impõe aos candidatos aos seus benefícios, se dá dentro de uma intersubjetividade que não é estranha ao método antropológico e sua ênfase na dialogia e na polifonia. A presença de antropólogos nestas bancas ou junto a estas políticas inclusivas não tem como objetivo dotá-las de um horizonte cientifico legítimo, mas, muito mais, permitir a devida problematização das questões que provocam, científicas destas perspectivas antropológicas do fazer desta ciência.

Como também havia discutido outro autor dos questionamento pós-modernos na Antropologia, George Marcus, apesar das tentativas de se aproximar o texto etnográfico de uma forma de literatura, a Antropologia continuou científica com seu lugar bem definido dentro das Ciências Humanas e Sociais. Se ele via nas discussões sobre identidade, raça, etnia novos temas que a Antropologia passou a incorporar aos seus estudos por serem temas que interessam, cada vez mais, aos seus interlocutores, devemos ter em mente que estes temas sempre foram constitutivos das ciências sociais no Brasil, já que diretamente relacionados ao tema maior da construção da identidade nacional (Marcus 1991: 197-221).

Este último tema sempre promoveu uma polarização metodológica das relações entre pesquisadores - ligados de alguma forma ao aparelho de Estado - e seus pesquisados - aqueles membros dos diversos grupos, minoritários ou não, que as Ciências Sociais estudam neste país. Uma melhor compreensão da questão de quem controla e define a produção de identidades se impõe, principalmente quando a discussão sobre identidades na modernidade passa a considerar que não podem ser vistas como uma formação estável quer na teoria quer na experiência social. Etnografias de identidades coletivas e individuais na modernidade devem partir do questionamento de conceitos como comunidades, localidades, identidades, memórias e tradições, e espero ter demonstrado, neste artigo, que as questões envolvendo definições e classificações sobre Etnia, Raça e Cor no Brasil, trazidas à tona pelos programas de cotas raciais nas IFES e suas bancas de verificação de identidades, onde ocorreram e ocorrem, se prestam de maneira exemplar para este tipo de exercício antropológico contemporâneo.

Antonio Carlos de Souza Lima e João Paulo Macedo e Castro chamam a atenção para que antropólogos, assim como os demais cientistas sociais, têm encontrado trabalho junto às políticas governamentais, na identificação de problemas sociais, na formulação de planos de ação governamental, em sua implementação e avaliação. Por isso mesmo, é preciso reconhecer, em primeiro lugar, que todas essas políticas não são geradas e avaliadas apenas dentro das fronteiras estritas dos territórios nacionais e da racionalidade imaginada ao Estado Nacional. Redes sociais complexas participam dos jogos de poder em torno do reconhecimento de um conjunto de relações sociais no qual os governos - federal, estadual, municipal - e suas agências irão intervir. O Estado não é um ente monolítico. Há muito que se discutir entre Estado, Governo e governança, formando um novo objeto antropológico (Souza Lima \& Macedo e Castro 2008: 351-397).

Conflitos em termos de interesses e significados são encobertos por uma suposta homogeneidade de signos compartilhados, constatação que é central para qualquer análise neste tipo de campo. A presença de antropólogos na definição, implementação e crítica aos recentes programas de inclusão racial foi marcante e decisiva, exigindo que uma reflexão sobre esta prática seja produzida, juntamente com a concomitante revisão e atualização conceitual que o tema e o debate antropológico em torno do mesmo exigem. Quando se precisa implantar uma política qualquer com populações minoritárias 
e marginalizadas, percebe-se o quão pouco se sabe a respeito dos problemas sociais cotidianos enfrentados por elas. Quais são as dinâmicas sociais em que essas comunidades estão envolvidas e como as políticas governamentais - como a lei de cotas - incide sobre elas? Como são definidas e como as populações atingidas por essas políticas se situam diante das mesmas e de seus agentes? Espero poder ter contribuído para um melhor entendimento sobre este tipo de problemática e apontado alguns caminhos propositivos para a pesquisa antropológica diante das políticas de promoção da igualdade racial no Brasil contemporâneo. ${ }^{10}$

\section{Marcos Silva da Silveira é doutor em Antropologia Social pela UnB e profes- sor do Departamento e do Programa de Pós-Graduação em Antropologia da UFPR.}

\section{REFERÊNCIAS BIBLIOGRÁFICAS}

ALMEIDA, Mauro William Barbosa de. 2003. "Relativismo antropológico e objetividade etnográfica". Campos 3: 9-29.

BEVILAQUA, Ciméa Barbato.2005. "Entre o previsível e o contingente: etnografia do processo de decisão sobre uma política de ação afirmativa”. Revista de Antropologia 48(1): 167-225.

CARVALHO, José Jorge. 2006. Inclusão étnica e racial no Brasil: a questão das cotas no ensino superior. São Paulo: Attar.

CLIFFORD, James. 1998. A experiência etnográfica: antropologia e literatura no século XX. Rio de Janeiro: Editora UFRJ.

DURHAM, Eunice Ribeiro. 2004. A dinâmica da Cultura. São Paulo: Cosac Naify.

FERREIRA, Letícia Camargo. 2014. "O etnógrafo, o burocrata e o "desaparecimento de pessoas" no Brasil: notas sobre pesquisar e participar da formulação de uma causa”. In Sérgio Ricardo Castilho \& Antonio Carlos de Souza Lima \& Carla Costa Teixeira (orgs.) Antropologia das práticas de poder: reflexões etnográficas entre burocratas, elites e corporações. Rio de Janeiro: Contracapa/Faperj.

GOLDMAN, Marcio. 1998. "Herzfeld, Michael. 1997 Cultural intimacy: Social poetics in the nation state. New York/London: Routledge. 266 pp.” Mana 4(2): 150-153. Resenha.

GOLDMAN, Marcio \& Gabriel Banaggia. 2017. “A política da má vontade na implantação das cotas étnico-raciais”. Revista de Antropologia 60(1): 16-34.

10 Agradeço, em primeiro lugar, à equipe editorial da Campos, em particular a Patrícia Carvalho Rosa, pela paciência na espera da versão final deste artigo. Conciliar as obrigações de professor, orientador, chefe de departamento com a produção intelectual é bem difícil. O texto acabou ficando pronto nas minhas férias de meio de ano. Agradeço também aos comentários de Marcos Alfonso Spiess e de Alexandre Plautz Lisboa, orientados por mim, que se dispuseram a ler uma primeira versão. 
GUIMARÃES, Antônio Sérgio Alfredo. 2008. “Raça, cor e outros conceitos analíticos”. In Osmundo Pinho \& Lívio Sansone (orgs.) Raça: novas perspectivas antropológicas. Salvador: EDUFBA/ ABA. 2a edição.

GUIMARÃES, Antônio Sérgio Alfredo \& Flávia Rios. 2014. "Cotas nas Universidades públicas”, Afro-Asia 50: 251-256.

LIMA, Márcia. 2005. “Ser negro no Brasil: do ônus ao bônus?” Horizontes Antropológicos 11(23): $258-261$.

MAIO, Marcos Chor \& Ricardo Ventura Santos. "Política de cotas, os 'olhos da sociedade' e os usos da antropologia: o caso do vestibular da Universidade de Brasília (UnB)”. Horizontes Antropológicos 11(23): 181-214.

MARCUS, George. 1991. "Identidades passadas, presentes e emergentes: requisitos para etnografias sobre a modernidade no final do século XX ao nível mundial”. Revista de Antropologia 34: 197-221.

OLIVEIRA, João Pacheco de. 1999. Ensaios de Antropologia Histórica. Rio de Janeiro: EdUFRJ. .2009. Pluralizando tradiçóes etnográficas. Cadernos do LEME 1(1):2-27.

PAIXÃO, Marcelo \& Luís Carvano. 2008. “A variável Cor ou Raça no interior dos sistemas censitários brasileiros." In Osmundo Pinho \& Lívio Sansone (orgs.) Raça: novas perspectivas antropológicas. Salvador: EDUFBA/ABA. $2^{\text {a }}$ edição.

PINHEIRO, Marielli Ramos. 2014. Cotas raciais na universidade pública brasileira: com a palavra, o cotista negro. Dissertação (Mestrado em Educação). Irati, PR: Universidade Estadual do Centro-Oeste (UNICENTRO).

SANTOS, Jocélio Teles dos (org.). 2012. Cotas nas universidades: análises dos processos de decisão. Salvador: Centro de Estudos Afro-Orientais da UFBA.

SANTOS, Jocélio Teles dos (org.). 2013. O impacto das cotas nas universidades brasileiras (20042012). Salvador: Centro de Estudos Afro-Orientais da UFBA.

SCHWARCZ, Lilia Moritz. 1998. "Nem Preto, nem branco, muito pelo contrário: cor e raça na intimidade”. In Fernando A. Novais (org.) História da vida privada no Brasil, vol.4. São Paulo: Companhia das Letras. p. 173-243.

SEYFERTH, Gyralda. 1995. "A invenção da raça e o poder discricionário dos estereótipos”. Anuário Antropológico 93: 175-203.

SILVA, Graziella Moraes \& Luciana de Souza Leão. 2012. "O paradoxo da mistura: identidades, desigualdades e percepção de discriminação entre brasileiros pardos”. RBCS 27(80): 117-133.

SOUZA LIMA, Antonio Carlos de \& João Paulo Macedo e Castro. 2008. “Política(s) Pública(s)”. In 
Osmundo Pinho \& Lívio Sansone (orgs.) Raça: novas perspectivas antropológicas. Salvador: EDUFBA/ABA. $2^{\text {a }}$ edição.

VALENTE, Ana Lúcia. 2006. ““Má vontade antropológica” e as cotas para negros nas universidades (ou usos e abusos da antropologia na pesquisa educacional II: Quando os antropólogos desaprendem)". Intermeio 12(24): 84-103. 


\title{
Algumas Questónes antropológicas a PARTir do PROGRAMA DE INCLU- SÃO RACIAL DA UNIVERSIDADE FEDERAL DO PARANÁ
}

Resumo: Pretendo refletir a respeito do Programa de Inclusão racial da Universidade Federal do Paraná, localizada em Curitiba. Esta política pública teve início em 2004, junto a um grande debate em torno das consequências das mesmas, polarizando bastante o ambiente antropológico brasileiro. A UFPR apresentou-se como um espaço interessante para esta discussão, na medida em que, localizada numa região de maioria branca de origem europeia, passou a receber estudantes negros e indígenas, gerando uma série de situações de relacionamento entre estes novos alunos, professores e funcionários. Em um novo quadro de relações institucional, bastante tenso, característico das negociações de identidade étnicas em curso, é possível afirmar que o tema da identidade étnico racial se impõe a todos, obrigando a reconsiderações das nossas noções de pessoa e de cidadãos brasileiros, assim como de diversas expectativas em torno do tema das relações raciais e das identidades étnicas no Brasil contemporâneo. Palavras-chave: cotas raciais; relações raciais; identidade étnica; UFPR

\section{SOME ANTHROPOLOGICAL ISSUES FROM THE RACIAL INCLUSION PROGRAM OF THE FEDERAL UNIVERSITY OF PARANÁ}

\begin{abstract}
I intend to reflect on the racial Inclusion Program of the Federal University of Paraná, located in Curitiba. This public policy began in 2004, next to a large debate around the consequences of them, quite polarizing the Brazilian anthropological environment. The UFPR showed to be an interesting space for this discussion, since it is located in a major white population area of European origin, began to receive black and indigenous students, generating a series of relationship issues between these new students, teachers and employees. In a new institutional relations framework, quite tense, characteristic of ethnic identity of negotiations, it is clear that the issue of racial ethnic identity is imposed on all, forcing reconsiderations of our notions of personhood and Brazilian citizenship, likewise different expectations surrounding the theme of race relations and ethnic identities in contemporary Brazil.
\end{abstract}

Keywords: Public Policy; Affirmative Policies; Racial Quotas; UFPR 